\title{
Urban Heat Islands and their Associated Impacts on Health
}

\author{
Dr Clare Heaviside \\ Environmental Change Institute, University of Oxford
}

\section{Summary}

Towns and cities generally exhibit higher temperatures than rural areas, for a number of reasons, including the effect that urban materials have on the natural balance of incoming and outgoing energy at the surface level, the shape and geometry of buildings, and the impact of anthropogenic heating. This localized heating means that towns and cities are often described as 'Urban Heat Islands' (UHIs). Urbanised areas modify local temperatures, but also other meteorological variables such as windspeed and direction, and rainfall patterns. The magnitude of the UHI for a given town or city tends to scale with the size of population, although smaller towns of just 1,000s of inhabitants can have an appreciable UHI effect. The UHI 'intensity' (the difference in temperature between a city centre and a rural reference point outside the city) is on average, on the order of a few degrees Celsius, but can peak at as much as $10^{\circ} \mathrm{C}$ in larger cities, given the right conditions. UHIs tend to be enhanced during heatwaves, when there is lots of sunshine and a lack of wind to provide ventilation and disperse the warm air. The UHI is most pronounced at night time, when rural areas tend to be cooler than cities, and urban materials radiate the energy they have stored during the day into the local atmosphere.

As well as affecting local weather patterns and interacting with local air pollution, the UHI can directly affect health through heat exposure, which can exacerbate minor illnesses, affect occupational performance, or increase the risk of hospitalization and even death. Urban populations can face serious risks to health during heatwaves whereby the heat associated with the UHI contributes additional warming. Heat related health risks are likely to increase in future against a background of climate change and increasing urbanisation throughout much of the world. However, there are ways to reduce urban temperatures and avoid some of the health impacts of the UHI, through behavioural changes, modification of buildings, or by urban scale interventions. In order to best evaluate the potential for interventions to reduce heat related impacts in future, it is important to understand the physical properties of the UHI, and the impact of the UHI on health.

\section{Keywords}

urban heat island, heat related mortality, urban environmental health, temperature, cities, climate change, land use change

\section{The Significance of the Urban Heat Island (UHI)}

Humans are responsible for causing significant modifications to the natural environment, most notably through large scale land use changes and the emission of greenhouse gases throughout the industrial era, which have led to increasing global temperature and more frequent extreme weather events (Field et al., 2012; IPCC, 2013). Local or regional modifications to land surfaces such as replacing vegetation with man-made materials, contributes to global climate change, but also has more local impacts. One of the most easily observed impacts of replacing natural surfaces with man-made materials such as concrete, tarmac and asphalt, is an increase in local air temperature, which can turn towns and cities into 'urban heat islands' (UHIs). This excess heat in urban areas is driven by the fact that urban materials modify the natural exchange of energy between the atmosphere and the surface of the Earth (the surface energy balance), as urban materials generally absorb and 
store solar energy during the daytime and release it at night. The lack of vegetation in urban areas also reduces evaporation rates so that local air temperature is increased through sensible heating. The geometry of buildings in cities means that heat gets trapped close to the surface and is not easily radiated to space (a reduced sky-view factor); anthropogenic heating also contributes to the UHI. The urban heat island intensity (the difference in temperature between the centre of a town or city and a rural reference point) is on the order of a few degrees on average, and usually reaches a maximum value at night time, when urban materials release their stored energy, warming the local environment, compared with natural environments, where heat storage is much lower.

The harmful effects of heat on human health are well documented, and include impacts ranging from mild illness and reduced occupational efficiency, to severe illness (e.g. cardiovascular, respiratory), hospitalization and even death (Basu, 2009). The UHI therefore poses a particular risk to health in terms of heat-related illness. This risk from heat is compounded by the fact that urban populations are often exposed to other hazards, such as air pollution, noise exposure, poor housing and social or economic disadvantages (Patz, Campbell-Lendrum, Holloway, \& Foley, 2005). On a global scale, many cities are expanding, and urban populations are growing, driven by economic and environmental pressures (United Nations, 2014). In the future, the pressures of climate change and increasing urbanisation will lead to increased risks to health through overheating in cities worldwide.

The risk to health from the UHI is not always easily captured, particularly when using global climate models, where the resolution is generally too coarse to resolve fine details such as urbanized areas. Increasing resolution comes at the cost of the requirement for increased computing power. This means that the UHI is a large source of uncertainty in terms of projecting future temperatures (Sherman \& Archibald, 2019) and we could potentially be under-estimating local or urban temperature impacts in future. Given the changing climate and with increasing pressure on urban communities, it is imperative that research continues to increase understanding of the physical processes driving the urban heat island, in order to quantify the likely impacts on health.. Implementation of potential solutions to reduce health risks in urban environments depends on successful understanding of the impacts.

\section{Measuring and Characterising the Urban Heat Island}

The UHI phenomenon was noted in the 1800s by Luke Howard, a pioneer of urban climate studies, who analysed the temperature in different parts of London (Howard, 1833). Despite extremely limited observations, Howard recognized the impact that London had on local climate, noting the artificial warmth induced by its structure, the population and consumption of fuel in fires. Howard defined the urban effect as the temperature difference between weather stations in comparatively urban and rural areas, denoted by $\Delta \mathrm{T}_{\mathrm{u}-\mathrm{r}}$, and defined the 'intensity' of the UHI effect in the same terms. The phenomenon of the urban effect on local climate became widely recognised, although a lack of observations meant that more in depth study of the urban heat island effect did not begin in earnest until the 1960s (Bornstein, 1968; Lowry, 1977; Oke, 1982). There is a wealth of research articles covering many aspects of the UHI. Only a selection is included here, and where possible, sources included have a health aspect.

\section{What causes the UHI effect?}


The UHI is largely driven by the fact that urban materials and morphology modify the natural surface energy balance (Oke, 1982). Urban geometry can limit the amount of heat radiated towards the sky, and surface roughness (the deviation from a flat surface due to objects like buildings), can reduce ventilation by disrupting wind flow, so that warm air does not get replaced by cooler air. The lack of moisture availability in towns and cities, means that less energy is used up by evaporation, and anthropogenic sources such as heating and air conditioning systems can contribute to local heating. All these factors contribute to the UHI effect to a greater or lesser extent (Oke, 1987).

During the daytime, urban materials such as concrete tend to store heat, which is released at night time in the form of long wave radiation, warming the local environment. In rural areas, when the incoming solar energy is 'switched off' after dark, temperatures drop, tend to reach a minimum and then start to climb again when the sun rises the next day. This differential heating of the local environment during night time is a key characteristic, making the UHI effect a nocturnal phenomenon, whereby urban temperatures tend not to fall as low as rural temperatures. A typical profile of temperature from a rural to an urban area is shown in Figure 1.

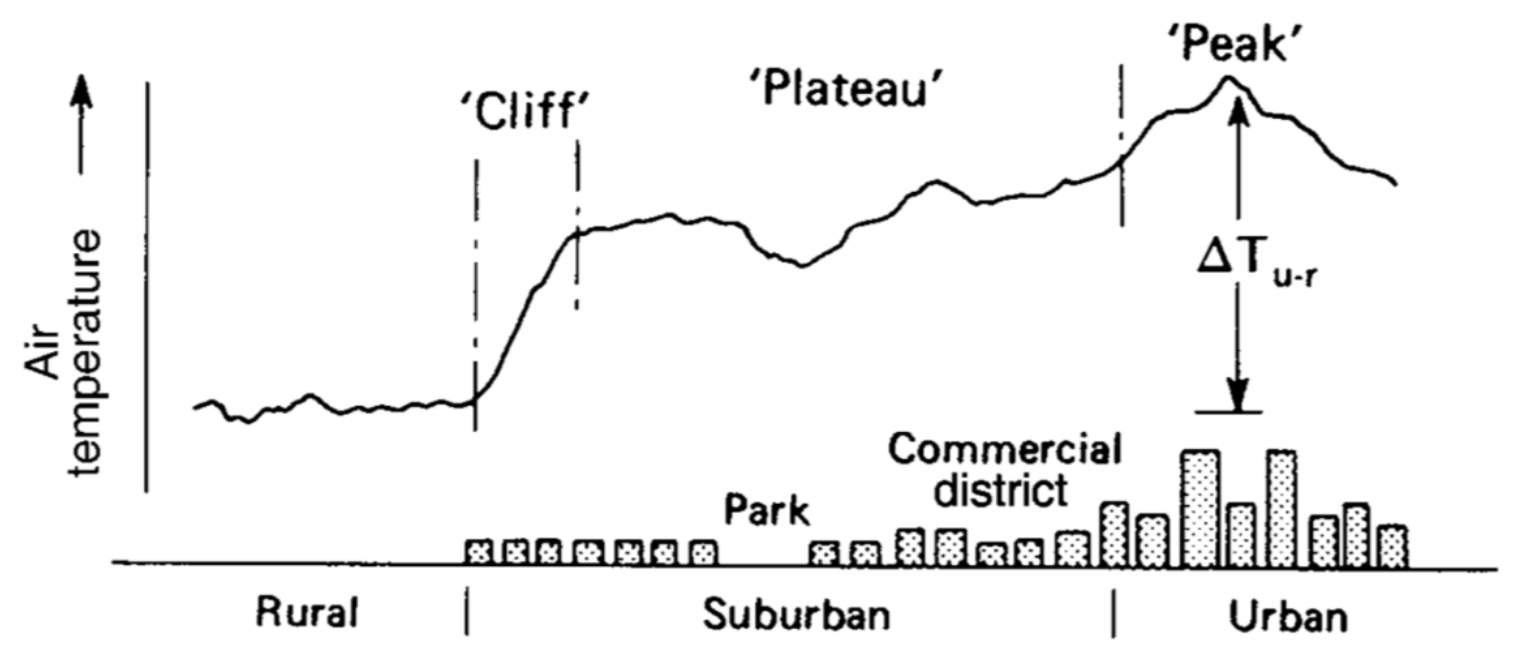

Figure 1. The classical illustration of a cross section of the urban heat island, showing temperature features such a temperature cliff at the edge of the urbanised area, a cooler spot coincident with a park, the plateau through the more densely populated parts of the city, and a temperature peak in the city centre. Reproduced from (Oke, 1987).

Certain weather conditions such as anticyclonic (high pressure) weather systems are particularly conducive to the formation of a strong UHI. Here, there is generally substantial solar heating in the daytime, low wind speeds, so that the warm air is not dispersed downwind of cities, and is instead trapped near the surface. In contrast, when there are strong winds and large amounts of cloud, the UHI tends to be weaker (Arnfield, 2003). The UHI can also interact with weather systems, affecting rainfall patterns and flood risk, disrupting surface winds and worsening air pollution (Collier, 2006). Under moderate wind conditions, urban heat can be advected horizontally away from cities, affecting areas downwind of the urban area (Heaviside, Cai, \& Vardoulakis, 2015a). Local weather and climate, and the particular physical characteristics of individual cities means that the UHI is unique to each town or city. 


\section{How large can the UHI intensity be?}

When averaged over time periods of a day or more, the UHI intensity is typically on the order of a few degrees. During the night time, however, UHI intensities can reach much larger maximums, particularly in large cities; if conditions are favourable, the intensity may reach 5 or $10^{\circ} \mathrm{C}$ (Bohnenstengel, Evans, Clark, \& Belcher, 2011; Gedzelman et al., 2003; Macintyre et al., 2018). The intensity of the UHI depends on various city specific factors such as urban density, local climate and land use, and tends to scale with the size of the population of an urban conurbation (Oke, 1973). However, cities or towns do not have to be particularly large, and may contain only a few thousand inhabitants in order to exhibit an UHI effect.

Settlements which are clustered close together, separated by more natural land surfaces can lead to the formation of an urban heat 'archipelago', with localised hotspots, rather than a simple isolated heat island (Taha 2017).

During extreme environmental conditions such as heatwaves, where regional temperatures are already anomalously high, temperatures in cities can reach levels which pose serious risks to health. Since the UHI is generally a nocturnal effect, there may be little respite from high temperatures, even during the night. Air pollution levels are often elevated during heatwaves, and in urban areas, which leads to further health risks (Fenech et al., 2019; H. Li et al., 2018).

\section{Challenges associated with measuring the UHI}

The UHI can be characterised as a surface or an air phenomenon, depending on whether the focus is on differences in temperature of the surface of the earth, of the air in the urban canopy layer (below roof height) or in the urban boundary layer (up to around $1 \mathrm{~km}$ above the surface) (Oke, 1987). The most relevant type of UHI in terms of effects on human health is usually defined in the air temperature of the canopy layer, which is represented by traditional static observations from weather stations measuring temperature at around $1.5 \mathrm{~m}$ above the ground (Grimmond, 2006).

Challenges arise because temperature monitoring sites tend to be sparsely situated, which makes measurements of the spatial features of the UHI difficult. Historically, weather stations were sited outside of the hottest parts of cities, as scientists recognised that urban effects were likely to have an impact on local temperatures. For example, in central London, one observation station is based in St James Park, where there is much more vegetation compared with the surrounding urban area. Measurements of the UHI intensity defined as the difference in temperature between urban and rural stations, may therefore be underestimated. Similarly, it is important that the rural station is sited in a truly rural location to capture the full intensity. A systematic review investigated 190 heat island studies and found that around half of them were lacking in quality, through measurement errors and by not fully reporting details of the methodology used (Stewart, 2011).

The advent of low-cost temperature sensors has enabled dense networks of temperature sensors to be deployed across cities. The relatively lower quality of the sensors compared with traditional weather stations is partly compensated by better spatial coverage; however this type of network can be expensive to set up and maintain (Bassett et al., 2016; Chapman et al., 2015; Sun et al., 2019). Networks of privately owned weather stations like Weather Underground (www.wunderground.com) can help to fill in the gaps and make use of citizen collected observations but it is difficult to measure the quality of this type of data. Moving transects (for example using vehicles) can provide observations in the form of a cross section of an urban area (D. B. Johnson, 1985; Taha et al., 2018). Transects give more spatial 
information than point measurements (albeit in only 2 dimensions) although there may be some error associated with the timing of measurements as the vehicle moves along a section.

Satellite data can support UHI studies, since they have the potential to provide detailed spatial information over large geographic areas, provide multi-spectral information and track changes over time. It is also possible to use sensors mounted on aircraft to provide custom high-resolution data, limited to small areas. Satellites measure the surface (skin) temperature of the earth, which has less relevance to human health, compared with air temperature. There are other limitations in using satellite data to characterise urban temperatures: there may be a lack of temporal information, as satellites typically only pass over an area once a day; data capture is limited to clear sky conditions, since clouds can block the satellite images; the angle of a satellite may affect which surface is being measured; and there is some uncertainty over retrieval of data - or the process of interpreting the data received by satellites, after attenuation in the atmosphere, in order to produce relevant temperature data. Some of the shortcomings described here may be overcome by employing a range of methodologies and using data from different sources, to help achieve effective characterization of the UHI.

\section{Using modelling techniques to characterize the UHI}

Increasingly, limitations in traditional observational techniques have been addressed by advances in weather and climate models. General Circulation Models (GCMs) generally provide global-scale simulations of weather and climate, and as such, are not able to resolve small scale features such as towns and cities. However regional models can be run at relatively high spatial and temporal resolution over discrete areas of interest and for specific time periods, which makes them highly suitable for urban heat island studies. Generally, these are referred to as mesoscale models, which relates to their horizontal resolution which ranges from a few $\mathrm{km}$ to a few hundred $\mathrm{km}$, so that they are on a smaller scale than (synoptic) weather systems, but larger scale than micro-climates.

Since land surfaces play such a important role in driving local climate conditions, it is essential that local land use is well represented in regional models, and that atmospheric processes near to the surface are well simulated. This can be achieved by employing boundary layer schemes within mesoscale models, which are designed to simulate local atmospheric conditions in the urban canopy layer (Barlow, 2014). One of the first mesoscale models to investigate the UHI of New York using a boundary layer scheme was the URBMET Urban Boundary Layer Model, a 2 dimensional scheme (Bornstein, 1975). Increased computing power and advances in modelling techniques have allowed boundary layer schemes in mesoscale models to parameterize turbulent fluxes in the lower boundary layer, enabling more detailed information about urban morphology and materials to be input, and for the option to include directly emitted anthropogenic heating sources (Salamanca et al., 2011).

In order to simulate conditions in the local boundary layer as accurately as possible, input data on a wide range of properties relating to building geometry and materials needs to be input into the boundary layer scheme (Grimmond \& Oke, 1999). Urban classification may be further broken down into more detailed urban sub categories, which reflect differences in building and street morphology between suburban and commercial neighbourhoods (Martilli, Clappier, \& Rotach, 2002). Since each city is unique in terms of land use, input data should be specific to the town or city to be modelled; there are also systematic differences in building types in different parts of the world, for example some cities are characterised by high rise reflective buildings, and some contain low rise or more dispersed clusters of 
buildings. Comparisons of model output with existing weather observations is essential to ensure satisfactory model performance.

In an attempt to standardise the process for classifying urban land use types for any city in the world, methods such as the Local Climate Zone mapping initiative have been developed, whereby land use classes have been extensively expanded to better represent urban areas anywhere in the world, and to provide some consistency for urban climate modelling studies (Stewart \& Oke, 2012). Detailed land use information can be derived from satellite images or vector data sources, and manipulated using Geographical Information Systems (GIS) to produce data suitable as input to a boundary layer scheme in a mesoscale model. A particular advantage of the use of mesoscale models with urban boundary layer schemes is the ability to vary parameters to test the potential impacts of various urban planning measures on the local climate.

Other types of models which do not explicitly attempt to simulate local weather and climate, use local observations, neural networks or artificial intelligence to predict local variations in temperatures across cities (Kolokotroni, Zhang, \& Giridharan, 2009; Theeuwes, Steeneveld, Ronda, \& Holtslag, 2017)

\section{Climate change and the UHI}

Urban areas both contribute to global climate change, through land use changes and greenhouse gas emissions, and are affected by it, through changing weather patterns. The UHI effect is likely to exacerbate the impacts of climate change, particularly in terms of increased temperatures and heatwaves. Although maximum temperatures in cities are likely to rise as a result of increasing global or regional temperatures, the effects of climate change on UHI intensity is less clear, and it is likely to depend strongly on the city in question, and local weather and climate at that particular location. One study for 54 US cities suggests that UHI intensity is not increasing with higher temperatures since rural areas are warming at a faster rate, potentially because rural areas are more sensitive to changes in larger scale weather conditions (Scott, Waugh, \& Zaitchik, 2018). Despite there being no clear signal of a relationship between climate change and UHI intensity, the urban temperature increment needs to be considered against a background of rising global temperatures. It is therefore necessary to combine projections of temperatures in urban areas with those of projected changes in global temperatures to anticipate the full extent of urban temperatures in future.

Trends in global mean temperatures derived from the global instrumental temperature record are routinely compiled by a number of international organisations around the world, including the Met Office in the UK, and NASA in the US. Although observational sites tend to be placed away from the densest urban areas, even slightly urbanised land use can positively bias temperature measurements, so these effects need to be corrected for (Bassett, Cai, Chapman, Heaviside, \& Thornes, 2017). Any changes to land-use throughout the instrumental record period which may influence surface air temperature are dealt with using statistical methods to correct any bias introduced by carefully comparing data from remote sites, uninfluenced by human activities, with urban sites. This careful handling and analysis of observations ensures a level of confidence that recent observed anthropogenic warming is not related to land use changes (Peterson, 2003). The IPCC stated that although the instrumental record over the last century did include urban heat island effects, these were mainly local effects, with a negligible influence on the global temperature trend (IPCC, 2007). 
Despite these reassurances, in 2010, a Californian based independent organisation named Berkeley Earth, with large amounts of donated funding, set about analysing land surface temperature data in order to determine whether or not urban temperatures, and changes in land use over recent decades, influenced the observed rise in global temperatures. The BEST (Berkeley Earth Science Temperature) Project reported that the observed warming trend was real, and that the results of their analysis echoed those of existing international published datasets (Tollefson, 2011). These results came as no surprise for climate and meteorological institutes, but were significant since the BEST Project was set up based on criticisms and concerns of the quality of climate change research and the reliability of the instrumental record. Many climate scientists saw the independent analysis of data as a positive addition to the literature, and the analysis of data by those with genuine scepticism of climate change was encouraged. Recent research suggests that because parts of the world which are warming most rapidly tend to have poor observational coverage (e.g. the Arctic), the temperature trend derived from global temperature records may actually underestimate the true temperature rise over the last century (Benestad, Erlandsen, Mezghani, \& Parding, 2019).

\section{How the Urban Heat Island Affects Health}

\section{The impacts of heat on health}

The effects of temperature on health are well researched and include mild illness through to increased risk of hospitalization and death (Basu, 2009; Guo et al., 2017, 2014). The health effects of heat and cold differ: cold tends to affect health over longer timescales (typically up to a few weeks) than heat, which is more immediate (effects up to a few days). Short periods of extreme heat can therefore lead to a spike in health effects, including increased mortality. For heat effects, mortality tends to increase above a threshold temperature; the shape of the response curve, and the position of the threshold temperature varies depending on the population in question. In countries with below average ambient temperatures, the threshold is often lower than in warmer countries, however, there are many factors which influence the shape of the temperature-mortality curve, including housing characteristics and socioeconomic status of the population (Baccini et al., 2008; A Gasparrini et al., 2015).

Climate change will mean increases in ambient temperature in future, which is likely to increase the risk of heat-related health impacts, globally, and particularly in already hot countries (Antonio Gasparrini et al., 2017; Hajat et al., 2014; Huang et al., 2011). Heatwaves lead to widespread health impacts, for example the heatwave of 2003 was thought to be responsible for around 70,000 deaths across Europe (Robine et al., 2008), and heatwave mortality in cities has been attributed to anthropogenic climate change (D. Mitchell et al., 2016). There is some evidence that people have adapted slightly to high temperatures over time, although it is unlikely that humans will be able to adapt at the observed rate of increasing temperatures (Arbuthnott, Hajat, Heaviside, \& Vardoulakis, 2016).

\section{Health risks in urban populations}

In 2007, for the first time, more of the world's population were classed as residing in urban than rural areas, and projections suggest that $66 \%$ of the world will live in urban areas by 2050 (United Nations, 2014). As well as growth in the proportion of urban vs rural dwellers, the total global population is increasing steadily and ageing, and urban areas are expanding, which puts increasing pressure on health care systems in many cities.

Urban heat poses a risk to health for urban populations, but there are many other risk factors which make urban populations particularly susceptible to the detrimental effects of the UHI. 
These include exposure to high levels of air pollution, traffic noise, poor water quality, poor housing and overcrowding (Heaviside, Macintyre, \& Vardoulakis, 2017; Vardoulakis, Dear, $\&$ Wilkinson, 2016). Often, the areas of cities which are most affected by urban heat, are colocated with areas where housing is of poor quality and where the populations may be more deprived in terms of social status, meaning the impacts of urban heat may disproportionately affect already vulnerable groups. Air conditioning (for those who can afford it) can be an effective way of reducing heat-related health impacts, however the downsides of implementing air conditioning run on non-renewable energy sources are overwhelming, in terms of greenhouse gas emissions and local anthropogenic heating (Lundgren-Kownacki, Hornyanszky, Chu, Olsson, \& Becker, 2018).

\section{Quantifying direct, heat related health impacts of the UHI}

Existing studies have quantified the impact of heat on health outcomes such as mortality or morbidity burden, but there are fewer which have attempted to quantify the direct impact of the UHI intensity on health. Quantification of this type requires combining health outcome data with exposure data. For example, analysing health data such as hospital admissions alongside urban temperature data can help to quantify the relative risk of morbidity or mortality depending on local heat exposure. When analysing mortality and morbidity statistics alongside temperatures in large cities such as Philadelphia and Massachusetts in the US, and Brisbane in Australia it was revealed that heatwave deaths and emergency hospitalisations are co-located with areas of the city with not only the highest exposure to heat, but also high population density, and with demographic indicators of susceptibility, such as the lowest incomes, and highest ages (Hattis, Ogneva-Himmelberger, \& Ratick, 2012; Hondula \& Barnett, 2014; D. P. Johnson \& Wilson, 2009). A health impact assessment for the whole of the US estimated that the impact of the UHI on heat related mortality was around 1.1 deaths per million population, although this was based on information from death certificates specifically highlighting temperature related effects, and is therefore likely to under-estimate the number of deaths where heat was a contributing factor (Lowe, 2016).

A small area cluster analysis across the city of Paris calculated health impacts from heat on the elderly (Benmarhnia, Kihal-Talantikite, Ragettli, \& Deguen, 2017). Results showed the adverse effects of particulate air pollution, which increased the risk of mortality during heatwaves, and the protective effect of green space. Another study used a case-control analysis to highlight urban-rural differences in health impacts (Laaidi et al., 2012). In Cyprus, the effects of heat stress on mortality has been quantified and the likely increased impacts due to climate change assessed (Heaviside, Tsangari, et al., 2016). By comparing cardiovascular and respiratory mortality counts in urban and rural parts of Cyprus during heatwave conditions, it was found that women in particular had an increased mortality risk from heat, in urban areas (Pyrgou \& Santamouris, 2018).

In an epidemiological study of London, the population was designated into 3 urban zones, from inner, mid and rural populations, and the relationship between temperature and mortality, and hence susceptibility to heat and cold for each separate group, was assessed to determine the level of adaptation to the effects of heat (Milojevic et al., 2016). There was some evidence of acclimatisation to heat in London, since susceptibility varied between the 3 zones. Another study in London provided quantitative estimates of heat-related mortality using high resolution modelling, and showed that different dwelling types, as well as UHI intensity were strongly related to the extent of health impacts (Taylor et al., 2015). 
One study used regional meteorological modelling simulations and epidemiological relationships for the West Midlands, the $2^{\text {nd }}$ most urbanised region, and Birmingham, the $2^{\text {nd }}$ largest city in the UK in order to quantify the direct effect of the UHI intensity on heatrelated mortality (Heaviside, Vardoulakis, \& Cai, 2016). By simulating local temperatures in the region during the 2003 heatwave for two scenarios - one with, and one without the effects of urban surfaces - and comparing the results of the two health impact assessments, it was reported that up to half of the heat-related mortality was associated with the UHI. This study also included projections of future temperature for the UK due to climate change, and including the UHI effect, and estimated a threefold increase in mortality for a 2003 type heatwave occurring in the 2080s (Heaviside, Vardoulakis, et al., 2016). Similarly, in the US, an analysis which included projections of urbanisation and climate change showed projected increased in heat-related mortality of up to $300 \%$ by the 2050s (Hondula, Georgescu, \& Balling, 2014).

\section{Identifying spatial variation in risk using mapping techniques}

Mapping how temperatures vary across urban areas can provide evidence for targeted, local action to minimise the effects of the UHI where it is most required. There is a wealth of temperature mapping studies for cities, globally, using a range of environmental data sources and techniques including satellite imagery and regional models with urban boundary layer schemes. However, increasingly, researchers have incorporated additional datasets with information about the local population, in order to give further knowledge on the potential spatial variations in health risks and vulnerability across a city.

Parts of cities with the highest UHI intensities tend to be more centrally located, with high population density and where populations are more likely to be socially disadvantaged, whereas suburbs tend to house more affluent populations (B. Mitchell \& Chakraborty, 2015). Social factors can modify an individual's risk or increase their vulnerability to the UHI. By including information about social and economic status of the population, it is possible to highlight parts of cities where populations are likely to be particularly susceptible to the impacts of heat. Many different indicators have been mapped alongside temperature and other exposure data in cities worldwide; examples of exposure metrics and susceptibility indicators are given in Table 1. By including multiple factors, researchers can help to identify areas most at risk from heat impacts, and can help policy makers to focus adaptation measures where the highest returns can be expected in terms of reducing health impacts.

Table 1. examples of metrics used for heat risk mapping studies

\begin{tabular}{ll}
\hline Example exposure metrics & Susceptibility indicators \\
\hline Daily mean air temperature (population & Age \\
weighted) & Dwelling type \\
Daily maximum temperature & Housing quality \\
Daily minimum temperature & Poverty \\
Summer mean/maximum temperatures & Social isolation \\
Urban Heat Island intensity & Ethnicity \\
Number of hot days & Education \\
Land surface temperature & Languages spoken \\
Air pollution concentration & Indices of multiple deprivation \\
Noise levels & Underlying health status \\
Vegetation index & Access to greenspace or cool areas \\
\hline
\end{tabular}




\author{
Access to air conditioning \\ Fuel poverty \\ Behavioural habits \\ Density of households \\ Diabetes \\ Income level \\ Welfare dependency
}

Accounting for population density, by weighting temperature metrics by population density is a more accurate measure of heat exposure, since population weighted temperature is likely to be higher than temperatures derived based on area averaging, for example by around $1^{\circ} \mathrm{C}$ in Birmingham, UK (Heaviside, Vardoulakis, et al., 2016). In the same city, satellite imagery illustrating the UHI intensity, combined with commercial data from a credit reference company was used to map vulnerability based on age and underlying illness (Tomlinson, Chapman, Thornes, \& Baker, 2011). High resolution regional modelling of this region showed that increasing levels of social vulnerability, based on indices of multiple deprivation, were correlated with increasing UHI intensity (Macintyre et al., 2018). Results also highlighted that housing types which are most associated with overheating (e.g. flats and apartments) tended to be located in the hottest parts of the city, as were hospitals and care homes.

In London, Taylor et al. mapped the 'triple jeopardy' that comes from the UHI, population age and dwelling type for a single hot day, based on a simulation from a regional climate model (Taylor et al., 2015). They found that dwelling type and UHI intensity were both strong determinants of heat-related mortality risk. Similar work comparing London and Madrid highlighted the highest levels of vulnerability were linked with summer energy poverty (Sanchez-Guevara, Núñez Peiró, Taylor, Mavrogianni, \& Neila González, 2019). Whilst wintertime poverty is more common in London, summertime poverty may become an increasing risk in the future in northern European cities.

In the US, research has targeted social vulnerability at the neighbourhood level for the New York area (Karimi, Nazari, Dutova, Khanbilvardi, \& Ghandehari, 2018), and looked at the potential for or difficulty in gaining refuge from heatwaves in Oregon (Voelkel, Hellman, Sakuma, \& Shandas, 2018). Mapping studies in China have highlighted the vulnerability of the elderly and those in mountainous regions (Hu, Yang, Zhong, Fei, \& Qi, 2017; W. Zhang, Zheng, \& Chen, 2019) and intra-urban comparisons have been carried out in Korea (Jänicke et al., 2019). One of only a few studies to look at heat risks in urban slums used remote sensing to characterise the locally high temperatures experienced in large and small slum areas in Ahmedabad, India, a risk factor which is likely to impact on an already vulnerable portion of the city population (Wang, Kuffer, Sliuzas, \& Kohli, 2019).

\title{
Heat vulnerability indices
}

Sometimes, vulnerability mapping is taken a step further for particular cities, and indices of risk or vulnerability are produced (Bao, $\mathrm{Li}, \& \mathrm{Yu}, 2015)$. These are highly localised, as risks vary between cities and populations, so that the exposure and susceptibility indicators are different for each index derived (Table 1). The most appropriate vulnerability factors for each location may be determined through reviews of epidemiological literature or based on expert opinion. Indices are either constructed based on weighting all factors equally and 
normalising, by undertaking some weighting of the index through expert judgement, or by principle component analysis (PCA) or cluster analysis.

One study used PCA based on 9 proxy measures of heat risk for the city of London, which were weighted according to their relative health impact (Wolf \& McGregor, 2013). The results showed evidence of clustering of multiple risks in areas of high vulnerability, such as high population density, welfare dependency and poor underlying health status. Similar PCA techniques were used to create a heat vulnerability index based on 5 classes for Puerto Rico, developed using satellite images and census data. The most relevant classes indicating vulnerability for this region were age, unemployment, education, health insurance coverage and social isolation (Méndez-Lázaro, Muller-Karger, Otis, McCarthy, \& Rodríguez, 2018). Similar indices have been constructed for China (Q. Chen, Ding, Yang, Hu, \& Qi, 2018) and Chicago in the US (D. P. Johnson, Stanforth, Lulla, \& Luber, 2012). The number of heat vulnerability index studies is increasing. However, in order to identify real risks from heat, it is important to validate the suitability of heat vulnerability indices by using recorded health data, such as emergency calls or hospitalizations (Bao et al., 2015). Multi-criteria decision analysis can be a valuable tool for policy makers, and allows them to apply weights of varying importance to a number of factors. These can then be tailored for different cities and population groups (Woods et al., 2016).

\section{Mitigation and Adaptation Measures to Reduce Urban Overheating}

The pressures of climate change, population growth and increasing urbanization will require concerted efforts to mitigate the UHI in order to try to avoid dangerous heat-related risks in the future. In the last decade, there have been a number of notable, deadly heatwaves throughout the world, and temperature records are regularly being broken. Since the Earth is committed to a certain level of global temperature rise already, even if greenhouse gas emissions were to stabilise (IPCC, 2019), adaptation measures will need to be deployed to prepare for anticipated changes as a matter of urgency, to minimise health impacts.

Once quantification of the risks and impacts of urban heat has been undertaken, it is possible to investigate the potential for interventions to reduce negative health impacts. Mitigation measures to reduce the intensity of the UHI can take a number of forms, but are broadly aligned with modifying the surface energy budget. For example, measures may reduce local heating through processes such as reflection of incoming solar energy, and minimising absorption of heat by urban materials, or by increasing evapotranspiration by providing more natural, green surfaces and increasing water availability. These interventions may be at the urban scale, for example, employing different types of road surfaces, providing shading by improved building design, or by increasing tree cover, which increases evapotranspiration and provides shade. At the building scale, UHI mitigation methods may include implementing green or reflective roofing materials, providing shutters on windows, or incorporating energy solutions by retrofitting dwellings and reducing local anthropogenic heat sources (Akbari \& Kolokotsa, 2016).

Adaptation of the population to increased risk of heat in future can be aided by public health interventions such as heat-health warning systems (Hajat et al., 2010). Ultimately, the level of adaptation of the population will be heavily influenced by population behaviour, and how people carry out their daily activity in general, as well as national and local policy measures. In order to reduce impacts and switch to sustainable, healthy cities, urban planners and local 
authorities should focus on the myriad health 'co-benefits' from policy decisions which aim to reduce the impacts of climate change in future whilst increasing population health, and potentially bringing economic benefits (Haines et al., 2009; Harlan \& Ruddell, 2011).

\section{Increasing the reflectivity of urban materials to reduce urban heat}

Urban materials tend to absorb and store energy throughout the day, and release it at night, leading to warming of the local environment. Modification to urban materials, for example by employing 'cool' (reflective) coatings for buildings and roads, has the potential to reduce the amount of energy stored and can therefore can help lower urban temperatures in summer time (Pasetto, Pasquini, Giacomello, \& Baliello, 2019; Pisello, 2017). Mitigation of urban heat by modification of the urban landscape is a heavily researched topic in itself and has been reviewed extensively elsewhere, e.g. (Salata et al., 2017). According to reviews of costs and benefits, one of the most cost-effective methods to reduce urban heat for UHI mitigation is through the use of cool roofs (Phelan et al., 2015; Zinzi \& Agnoli, 2012). An urban climate modelling study suggested that temperatures can be reduced by up to $4^{\circ} \mathrm{C}$ in the daytime and $1^{\circ} \mathrm{C}$ at night in Rome, by increasing the albedo of roofs, walls and roads (Morini, Touchaei, Rossi, Cotana, \& Akbari, 2018). In Stuttgart, the UHI intensity was reduced by more than $1^{\circ} \mathrm{C}$ in a similar modelling study, although there were potential impacts on increased local air pollution, when increasing the albedo of roofs (Fallmann, Forkel, \& Emeis, 2016).

There have been attempts to explicitly estimate the health impacts of various UHI mitigation strategies. This kind of assessment is essential in order to best inform policy makers and town planners of the relative costs and benefits of interventions. For example, modelling the potential numbers of deaths avoided based on maximising reflectivity of roofs reveals that up to 45 deaths per year could be avoided in the city of New York (Susca, 2012). It was also reported that cool roofs were the most effective UHI mitigation method in terms of reducing numbers of emergency service calls in Arizona (Silva, Phelan, \& Golden, 2010). When including climate projections into an assessment of health impacts of changes in surface reflectivity and vegetation cover, it was estimated that 40-99\% of the projected impacts of climate change on health could be offset by a combination of UHI mitigation schemes (Stone $\mathrm{Jr}$ et al., 2014). There is likely to be disparity in the effectiveness of urban heat management schemes by age, income, ethnicity and other factors (Vargo, Stone, Habeeb, Liu, \& Russell, 2016).

In the UK, modelled simulations of the effect of cool roofs have shown health benefits, with increasing reflectivity in a UK city leading to reduced daytime maximum temperatures, and a corresponding decrease in heat related mortality of up to $25 \%$ of the total estimated heat mortality associated with the UHI intensity (Macintyre \& Heaviside, 2019). The largest health benefits were seen when implementing cool roofs on commercial and industrial properties, rather than residential areas. In London, the impact of a range of building level modifications was simulated in terms of indoor temperature and heat-related mortality impacts, with the main result showing that adding and using shutters on windows can be an extremely protective adaptation measure (Taylor et al., 2018).

\section{Urban greening and the benefits of green infrastructure to health}

Whilst the impacts of reflective surfaces bring about direct benefits to health through reduced local temperatures, the health implications of various types of green infrastructure are more complex, and there are likely to be health benefits in addition to heat reduction. Green infrastructure to mitigate UHI effects may include increasing the areas of parks and recreational areas, increasing the green fraction of existing urban areas, the use of green walls 
and roofs and the planting of trees (Marando, Salvatori, Sebastiani, Fusaro, \& Manes, 2019; Price, Jones, \& Jefferson, 2015). The use of water bodies (sometimes called 'blue spaces') can also mitigate urban heat (Steeneveld, Koopmans, Heusinkveld, \& Theeuwes, 2014). These nature-based solutions can reduce local temperatures through increased evapotranspiration, but are likely to have other benefits. For example, there are reported benefits to mental health and wellbeing from access to green spaces and increased levels of activity and recreation from parks and gardens (Fleming et al., 2018; Livesley, McPherson, \& Calfapietra, 2016; Wheeler et al., 2015).

It is important to consider the optimum location or formation of green infrastructure. For example, a study in Phoenix, Arizona found that optimal positioning, and adding only $1 \%$ of new green space could cool surface temperatures by $1-2^{\circ} \mathrm{C}$, and that dispersed patterns lead to regional cooling, whereas clustered patterns are better for more local cooling. (Y. Zhang, Murray, \& Turner, 2017). For Chicago in the US, a multi-disciplinary approach used urban climate modelling combined with social and economic data to identify vulnerable population groups who would be most likely to benefit from green roofs (Sharma et al., 2018).

Combinations of changing roofs to green or cool surfaces may be appropriate in different cases; structural factors, local humidity and the ease of irrigation should be taken into consideration when planning green roofs (D. Li \& Bou-Zeid, 2013). Although the impacts on health of green infrastructure appear to be overwhelmingly positive, there may also be some risks to health through increased aeroallergens or disease vectors such as urban ticks or mosquitoes when increasing urban greenery (Salmond et al., 2016).

The benefits of green infrastructure are difficult to quantify but estimating the health or economic value of policies which use green infrastructure to reduce the impacts of the UHI can be useful to urban planners, and these resources are growing in number. For example, a comprehensive health impact assessment for the city of Melbourne in Australia modelled the effect of increasing the numbers of trees throughout the city, finding substantial reductions in heat-related mortality (D. Chen et al., 2014). A cost-benefit analysis of implementing green roofs in the city of Lisbon, Portugal looked at financial, economic and socio-environmental aspects of implementing green roofs. The results suggested that there were positive social benefits, but these came at a financial cost for implementation (Teotónio, Silva, \& Cruz, 2018). Also in Lisbon, it was found that living near to green and blue space in urban areas was associated with decreased mortality for elderly populations (Burkart et al., 2015). Although positive health effects have been observed in relation to green and blue spaces, it is not always easy to determine a causal relationship (de Keijzer et al., 2016; Wheeler et al., 2015).

\section{Planning for Future Urban Environments: Challenges Ahead}

The effects of climate change are already apparent, as demonstrated through increasing global temperatures, and more frequent heatwave events. Temperature records are being broken with increasing frequency, and by wider margins; for example, June in 2019 was the hottest ever recorded, with temperatures at around $2^{\circ} \mathrm{C}$ higher than usual in Europe (https://climate.copernicus.eu/record-breaking-temperatures-june). Projections show that the warmest parts of the world are likely to see the largest heat-related health impacts in coming decades (Antonio Gasparrini et al., 2017), and increasing populations and greater degrees of urbanisation will expose more of the earth's population to dangerous levels of urban heat in 
future. Humankind is already committed to a certain level of climate warming, but in order to avoid catastrophic and irreversible effects in the future, it will be necessary to employ major, and integrated changes to our environment and way of life, particularly in our towns and cities.

As research outputs give us more insight into urban environmental health risks, and climate models are able to capture urban effects on climate more clearly, the risks will become clearer. An effective public health response will become increasingly important, with widespread heat-health warning systems employed where they were previously absent, and with acknowledgement that urban populations are likely to be more at risk (Public Health England, 2015).

Development of new urban areas should be carefully designed and as sustainable as possible in order to avoid the mistakes of the past. As far as possible we should retrofit and improve our urban environments, treating the causes of ill health in an integrated manner. There are considerable co-benefits to be had from living in sustainable cities, such as increased active travel, improved air quality, and improved mental health and wellbeing (Haines et al., 2009).

Multi-disciplinary collaborations, and effective communication between different sectors, including scientists, architects, engineers and public health professionals, will ensure research recommendations are acted on. Research outputs need to be accessible to policy makers in order to have the biggest impact. Public knowledge of environmental issues such as climate change is increasing. The scientific and public health communities should build on this public engagement to drive widespread behavioural changes and to help influence policy and planning measures.

\section{References}

Akbari, H., \& Kolokotsa, D. (2016). Three decades of urban heat islands and mitigation technologies research. Energy and Buildings, 133, 834-852. https://doi.org/10.1016/j.enbuild.2016.09.067

Arbuthnott, K., Hajat, S., Heaviside, C., \& Vardoulakis, S. (2016). Changes in population susceptibility to heat and cold over time: assessing adaptation to climate change. Environmental Health, 15(1), 72-93. https://doi.org/10.1186/s12940-016-0102-7

Arnfield, A. J. (2003). Two decades of urban climate research: a review of turbulence, exchanges of energy and water, and the urban heat island. International Journal of Climatology, 23(1), 1-26. https://doi.org/10.1002/joc.859

Baccini, M., Biggeri, A., Accetta, G., Kosatsky, T., Katsouyanni, K., Analitis, A., ... Michelozzi, P. (2008). Heat effects on mortality in 15 European cities. Epidemiology, 19(5), 711-719. Retrieved from http://www.scopus.com/inward/record.url?eid=2-s2.050549104811\&partnerID $=40$

Bao, J., Li, X., \& Yu, C. (2015). The Construction and Validation of the Heat Vulnerability Index, a Review. International Journal of Environmental Research and Public Health, 12(7), 7220-7234. https://doi.org/10.3390/ijerph120707220

Barlow, J. F. (2014). Progress in observing and modelling the urban boundary layer. Urban Climate, 10, 216-240. https://doi.org/10.1016/J.UCLIM.2014.03.011

Bassett, R., Cai, X., Chapman, L., Heaviside, C., \& Thornes, J. E. (2017). The Effects of Heat Advection on UK Weather and Climate Observations in the Vicinity of Small Urbanized Areas. Boundary-Layer Meteorology, 165(1), 181-196. https://doi.org/10.1007/s10546-017-0263-0 
Bassett, R., Cai, X., Chapman, L., Heaviside, C., Thornes, J. E., Muller, C. L., ... Warren, E. L. (2016). Observations of urban heat island advection from a high-density monitoring network. Quarterly Journal of the Royal Meteorological Society, 142(699), 2434-2441. https://doi.org/10.1002/qj.2836

Basu, R. (2009). High ambient temperature and mortality: A review of epidemiologic studies from 2001 to 2008. Environmental Health: A Global Access Science Source, 8(1). Retrieved from http://www.scopus.com/inward/record.url?eid=2-s2.071049181519\&partnerID=40\&md5=890eff6bac86213b3d01a1d216c1ecc6

Benestad, R. E., Erlandsen, H. B., Mezghani, A., \& Parding, K. M. (2019). Geographical Distribution of Thermometers Gives the Appearance of Lower Historical Global Warming. Geophysical Research Letters, 2019GL083474. https://doi.org/10.1029/2019GL083474

Benmarhnia, T., Kihal-Talantikite, W., Ragettli, M. S., \& Deguen, S. (2017). Small-area spatiotemporal analysis of heatwave impacts on elderly mortality in Paris: A cluster analysis approach. Science of The Total Environment, 592, 288-294. https://doi.org/10.1016/J.SCITOTENV.2017.03.102

Bohnenstengel, S. I., Evans, S., Clark, P. A., \& Belcher, S. E. (2011). Simulations of the London urban heat island. Quarterly Journal of the Royal Meteorological Society, 137(659), 1625-1640. Retrieved from http://www.scopus.com/inward/record.url?eid=2s2.0-80052531593\&partnerID $=40 \& m d 5=8364932 \mathrm{~d} 143833 \mathrm{a} 6654 \mathrm{~b} 0525 \mathrm{c} 55 \mathrm{~d} 0391$

Bornstein, R. D. (1968). Observations of the Urban Heat Island Effect in New York City. Journal of Applied Meteorology, 7(4), 575-582. https://doi.org/10.1175/15200450(1968)007<0575:OOTUHI>2.0.CO;2

Bornstein, R. D. (1975). The Two-Dimensional URBMET Urban Boundary Layer Model. Journal of Applied Meteorology, 14(8), 1459-1477. https://doi.org/10.1175/15200450(1975)014<1459:TTDUUB > 2.0.CO;2

Burkart, K., Meier, F., Schneider, A., Breitner, S., Canário, P., Alcoforado, M. J., ... Endlicher, W. (2015). Modification of Heat-Related Mortality in an Elderly Urban Population by Vegetation (Urban Green) and Proximity to Water (Urban Blue): Evidence from Lisbon, Portugal. https://doi.org/10.1289/ehp.1409529

Chapman, L., Muller, C. L., Young, D. T., Warren, E. L., Grimmond, C. S. B., Cai, X. M., \& Ferranti, E. J. S. (2015). The birmingham urban climate laboratory: An open meteorological test bed and challenges of the Smart city. Bulletin of the American Meteorological Society, 96(9), 1545-1560. https://doi.org/10.1175/BAMS-D-1300193.1

Chen, D., Wang, X., Thatcher, M., Barnett, G., Kachenko, A., \& Prince, R. (2014). Urban vegetation for reducing heat related mortality. Environmental Pollution, 192, 275-284. https://doi.org/10.1016/j.envpol.2014.05.002

Chen, Q., Ding, M., Yang, X., Hu, K., \& Qi, J. (2018). Spatially explicit assessment of heat health risk by using multi-sensor remote sensing images and socioeconomic data in Yangtze River Delta, China. International Journal of Health Geographics, 17(1), 15. https://doi.org/10.1186/s12942-018-0135-y

Collier, C. G. (2006). The impact of urban areas on weather. Quarterly Journal of the Royal Meteorological Society, 132(614), 1-25. https://doi.org/10.1256/qj.05.199

de Keijzer, C., Agis, D., Ambrós, A., Arévalo, G., Baldasano, J. M., Bande, S., ... Basagaña, $X$. (2016). The association of air pollution and greenness with mortality and life expectancy in Spain: A small-area study. Environment International. https://doi.org/10.1016/j.envint.2016.11.009

Fallmann, J., Forkel, R., \& Emeis, S. (2016). Secondary effects of urban heat island mitigation measures on air quality. Atmospheric Environment, 125, 199-211. 
https://doi.org/10.1016/j.atmosenv.2015.10.094

Fenech, S., Doherty, R. M., Heaviside, C., Macintyre, H. L., O’Connor, F. M., Vardoulakis, S., ... Agnew, P. (2019). Meteorological drivers and mortality associated with $\mathrm{O} 3$ and PM2.5 air pollution episodes in the UK in 2006. Atmospheric Environment.

https://doi.org/10.1016/J.ATMOSENV.2019.06.030

Field, C. B., Barros, V. R., Stocker, T. F., Qin, D., Dokken, D. J., Ebi, K. L., ... Midgley, P. M. (2012). Managing the Risks of Extreme Events and Disasters to Advance Climate Change Adaptation. A Special Report of Working Groups I and II of the Intergovernmental Panel on Climate Change, 1-594. https://doi.org/10.1017/CBO9781139177245

Fleming, L. E., Leonardi, G. S., White, M. P., Medlock, J., Alcock, I., Macintyre, H. L., ... Duarte-Davidson, R. (2018). Beyond climate change and health: Integrating broader environmental change and natural environments for public health protection and promotion in the UK. Atmosphere, 9(7). https://doi.org/10.3390/atmos9070245

Gasparrini, A, Guo, Y., Hashizume, M., Lavigne, E., Zanobetti, A., Schwartz, J., ...

Armstrong, B. (2015). Mortality risk attributable to high and low ambient temperature:

A multicountry observational study. The Lancet, 386(9991), 369-375. https://doi.org/10.1016/S0140-6736(14)62114-0

Gasparrini, Antonio, Guo, Y., Sera, F., Vicedo-Cabrera, A. M., Huber, V., Tong, S., ... Armstrong, B. (2017). Projections of temperature-related excess mortality under climate change scenarios. The Lancet Planetary Health, 1(9), e360-e367. https://doi.org/10.1016/S2542-5196(17)30156-0

Gedzelman, S. D., Austin, S., Cermak, R., Stefano, N., Partridge, S., Quesenberry, S., \& Robinson, D. A. (2003). Mesoscale aspects of the Urban Heat Island around New York City. Theoretical and Applied Climatology, 75(1-2).

Grimmond, C. S. B. (2006). Progress in measuring and observing the urban atmosphere. Theoretical and Applied Climatology, 84(1-3), 3-22. https://doi.org/10.1007/s00704005-0140-5

Grimmond, C. S. B., \& Oke, T. R. (1999). Aerodynamic Properties of Urban Areas Derived from Analysis of Surface Form. Journal of Applied Meteorology, 38(9), 1262-1292. https://doi.org/10.1175/1520-0450(1999)038<1262:APOUAD>2.0.CO;2

Guo, Y., Gasparrini, A., Armstrong, B. G., Tawatsupa, B., Tobias, A., Lavigne, E., ... Tong, S. (2017). Heat Wave and Mortality: A Multicountry, Multicommunity Study. Environmental Health Perspectives, 125(8), 087006. https://doi.org/10.1289/EHP1026

Guo, Y., Gasparrini, A., Armstrong, B., Li, S., Tawatsupa, B., Tobias, A., ... Williams, G. (2014). Global variation in the effects of ambient temperature on mortality: a systematic evaluation. Epidemiology (Cambridge, Mass.), 25(6), 781-789. https://doi.org/10.1097/EDE.0000000000000165

Haines, A., McMichael, A. J., Smith, K. R., Roberts, I., Woodcock, J., Markandya, A., ... Wilkinson, P. (2009). Public health benefits of strategies to reduce greenhouse-gas emissions: overview and implications for policy makers. The Lancet, 374(9707), 21042114. Retrieved from http://www.scopus.com/inward/record.url?eid=2-s2.072049108387\&partnerID $=40$

Hajat, S., Sheridan, S. C., Allen, M. J., Pascal, M., Laaidi, K., Yagouti, A., ... Kosatsky, T. (2010). Heat-Health Warning Systems: A Comparison of the Predictive Capacity of Different Approaches to Identifying Dangerously Hot Days. American Journal of Public Health, 100(6), 1137-1144. https://doi.org/10.2105/AJPH.2009.169748

Hajat, S., Vardoulakis, S., Heaviside, C., Eggen, B., Vardoulakis, S., Heaviside, C., ... Stedman, J. (2014). Climate change effects on human health: Projections of temperature-related mortality for the UK during the 2020s, 2050s and 2080s. Journal of 
Epidemiology and Community Health, 68(7), 641-648. https://doi.org/10.1136/jech2013-20244910.1029/2007JD008914; Kodra, E., Steinhaeuser, K., Ganguly, A.R., Persisting cold extremes under 21st-century warming scenarios (2011) Geophys Res Lett, 38, pp. L08705. , doi:10.1029/2011GL047103; Vardoulakis, S., Heaviside, C., Health effects of climate change in the UK 2012-current evidence, recommendations and research gaps (2012) Health Prot Agency, p. 236; Armstrong, B.G., Chalabi, Z., Fenn, B., Association of mortality with high temperatures in a temperate climate:

Harlan, S. L., \& Ruddell, D. M. (2011). Climate change and health in cities: Impacts of heat and air pollution and potential co-benefits from mitigation and adaptation. Current Opinion in Environmental Sustainability, 3(3), 126-134.

https://doi.org/10.1016/j.cosust.2011.01.001

Hattis, D., Ogneva-Himmelberger, Y., \& Ratick, S. (2012). The spatial variability of heatrelated mortality in Massachusetts. Applied Geography, 33(1), 45-52. https://doi.org/10.1016/j.apgeog.2011.07.008

Heaviside, C., Cai, X.-M., \& Vardoulakis, S. (2015a). The effects of horizontal advection on the urban heat island in Birmingham and the West Midlands, United Kingdom during a heatwave. Quarterly Journal of the Royal Meteorological Society, 141(689), 14291441. https://doi.org/10.1002/qj.2452

Heaviside, C., Cai, X. M., \& Vardoulakis, S. (2015b). The effects of horizontal advection on the urban heat island in Birmingham and the West Midlands, United Kingdom during a heatwave. Quarterly Journal of the Royal Meteorological Society, 141(689), 14291441. https://doi.org/10.1002/qj.2452

Heaviside, C., Macintyre, H., \& Vardoulakis, S. (2017). The Urban Heat Island: Implications for Health in a Changing Environment. Current Environmental Health Reports, 4(3), 296-305. https://doi.org/10.1007/s40572-017-0150-3

Heaviside, C., Tsangari, H., Paschalidou, A., Vardoulakis, S., Kassomenos, P., Georgiou, K., \& Yamasaki, E. (2016). Heat-related mortality in Cyprus for current and future climate scenarios. Science of the Total Environment, 569570, 627-633. https://doi.org/10.1016/j.scitotenv.2016.06.138

Heaviside, C., Vardoulakis, S., \& Cai, X.-M. (2016). Attribution of mortality to the urban heat island during heatwaves in the West Midlands, UK. Environmental Health: A Global Access Science Source, 15. https://doi.org/10.1186/s12940-016-0100-9

Hondula, D. M., \& Barnett, A. G. (2014). Heat-related morbidity in Brisbane, Australia: Spatial variation and area-level predictors. Environmental Health Perspectives, 122(8), 831-836. https://doi.org/10.1289/ehp.130749610.1289/ehp.1002313; (2006), http://abs.gov.au/websitedbs/censushome.nsf/home/historicaldata2006, Australian Bureau of Statistics, 2006 Census Data. Available, accessed 1 July 2012Barnett, A.G., Temperature and cardiovascular deaths in the US elderly: Changes over time (2007) Epidemiology, 18, pp. 369-372; Barnett, A.G., Hajat, S., Gasparrini, A., Rocklöv, J., Cold and heat waves in the United States (2012) Environ Res, 112, pp. 218-224; Bassil, K.L., Cole, D.C., Moineddin, R

Hondula, D. M., Georgescu, M., \& Balling, R. C. (2014). Challenges associated with projecting urbanization-induced heat-related mortality. Science of The Total Environment, 490, 538-544. https://doi.org/10.1016/j.scitotenv.2014.04.130

Howard, L. (1833). Climate of London deduced from meteorological observations. 3 rd edition. Harvery and Darton, London.

Hu, K., Yang, X., Zhong, J., Fei, F., \& Qi, J. (2017). Spatially Explicit Mapping of Heat Health Risk Utilizing Environmental and Socioeconomic Data. Environmental Science \& Technology, 51(3), 1498-1507. https://doi.org/10.1021/acs.est.6b04355

Huang, C., Barnett, A. G., Wang, X., Vaneckova, P., FitzGerald, G., \& Tong, S. (2011). 
Projecting future heat-related mortality under climate change scenarios: a systematic review. Environ Health Perspect, 119(12), 1681-1690.

https://doi.org/10.1289/ehp.1103456

IPCC. (2007). Summary for Policymakers. In: Climate Change 2007: The Physical Science Basis. Contribution of Working Group I to the Fourth Assessment Report of the Intergovernmental Panel on Climate Change. Cambridge University Press, Cambridge, United Kingdom and New .

IPCC. (2013). Summary for Policymakers. In: Climate Change 2013: The Physical Science Basis. Contribution of Working Group I to the Fifth Assessment Report of the Intergovernmental Panel on Climate Change [Stocker, T.F., D. Qin, G.-K. Plattner, M. Tignor, S.K. Allen, J.

IPCC. (2019). Summary for Policymakers. In: Global Warming of $1.5^{\circ}$ C. An IPCC Special Report on the impacts of global warming of $1.5^{\circ} \mathrm{C}$ above pre-industrial levels and related global greenhouse gas emission pathways, in the context of strengthening the global response to. Retrieved from https://www.ipcc.ch/sr15/chapter/summary-forpolicy-makers/

Jänicke, B., Holtmann, A., Kim, K. R., Kang, M., Fehrenbach, U., \& Scherer, D. (2019). Quantification and evaluation of intra-urban heat-stress variability in Seoul, Korea. International Journal of Biometeorology, 63(1), 1-12. https://doi.org/10.1007/s00484018-1631-2

Johnson, D. B. (1985). Urban modification of diurnal temperature cycles in Birmingham, UK. Journal of Climatology, 5(2), 221-225. Retrieved from http://www.scopus.com/inward/record.url?eid=2-s2.00022236348\&partnerID $=40 \& \mathrm{md} 5=\mathrm{c} 6 \mathrm{e} 962 \mathrm{aa} 13 \mathrm{cb} 8 \mathrm{ebff5} 16826 \mathrm{c} 9 \mathrm{e} 3617 \mathrm{~b} 5$

Johnson, D. P., Stanforth, A., Lulla, V., \& Luber, G. (2012). Developing an applied extreme heat vulnerability index utilizing socioeconomic and environmental data. Applied Geography, 35(1-2), 23-31. https://doi.org/10.1016/j.apgeog.2012.04.006

Johnson, D. P., \& Wilson, J. S. (2009). The socio-spatial dynamics of extreme urban heat events: The case of heat-related deaths in Philadelphia. Applied Geography, 29(3), 419434. https://doi.org/10.1016/j.apgeog.2008.11.004

Karimi, M., Nazari, R., Dutova, D., Khanbilvardi, R., \& Ghandehari, M. (2018). A conceptual framework for environmental risk and social vulnerability assessment in complex urban settings. Urban Climate, 26, 161-173. https://doi.org/10.1016/J.UCLIM.2018.08.005

Kolokotroni, M., Zhang, Y., \& Giridharan, R. (2009). Heating and cooling degree day prediction within the London urban heat island area. Building Services Engineering Research and Technology, 30(3), 183-202. https://doi.org/10.1177/0143624409104733

Laaidi, K., Zeghnoun, A., Dousset, B., Bretin, P., Vandentorren, S., Giraudet, E., \& Beaudeau, P. (2012). The impact of heat islands on mortality in Paris during the August 2003 heat wave. Environmental Health Perspectives, 120(2), 254-259. Retrieved from http://www.scopus.com/inward/record.url?eid=2-s2.084856742151\&partnerID=40\&md5=eab6cda62bd6a61beed60915d1d3d182

Li, D., \& Bou-Zeid, E. (2013). Synergistic interactions between urban heat islands and heat waves: The impact in cities is larger than the sum of its parts. Journal of Applied Meteorology and Climatology, 52(9), 2051-2064. https://doi.org/10.1175/JAMC-D-1302.110.1155/2010/ 230365; Bateni, S.M., Entekhabi, D., Relative efficiency of land surface energy balance components (2012) Water Resour. Res., 48. , doi:10.1029/2011WR011357; Bou-Zeid, E., Overney, J., Rogers, B.D., Parlange, M.B., The effects of building representation and clustering in largeeddy simulations of flows in urban canopies (2009) Bound.-Layer Meteor., 132, pp. 415-436; Brutsaert, W., 
Evaporation into the Atmosphere: Theory, History, and Applications (1982), p. 29

Li, H., Meier, F., Lee, X., Chakraborty, T., Liu, J., Schaap, M., \& Sodoudi, S. (2018). Interaction between urban heat island and urban pollution island during summer in Berlin. Science of The Total Environment, 636, 818-828. https://doi.org/10.1016/J.SCITOTENV.2018.04.254

Livesley, S. J., McPherson, G. M., \& Calfapietra, C. (2016). The Urban Forest and Ecosystem Services: Impacts on Urban Water, Heat, and Pollution Cycles at the Tree, Street, and City Scale. Journal of Environment Quality, 45(1), 119. https://doi.org/10.2134/jeq2015.11.0567

Lowe, S. A. (2016). An energy and mortality impact assessment of the urban heat island in the US. Environmental Impact Assessment Review, 56, 139-144. https://doi.org/10.1016/j.eiar.2015.10.004

Lowry, W. P. (1977). Empirical Estimation of Urban Effects on Climate: A Problem Analysis. Journal of Applied Meteorology, 16(2), 129-135. https://doi.org/10.1175/1520-0450(1977)016<0129:EEOUEO>2.0.CO;2

Lundgren-Kownacki, K., Hornyanszky, E. D., Chu, T. A., Olsson, J. A., \& Becker, P. (2018). Challenges of using air conditioning in an increasingly hot climate. International Journal of Biometeorology, 62(3), 401-412. https://doi.org/10.1007/s00484-017-1493-z

Macintyre, H. L., \& Heaviside, C. (2019). Potential benefits of cool roofs in reducing heatrelated mortality during heatwaves in a European city. Environment International, 127, 430-441. https://doi.org/10.1016/J.ENVINT.2019.02.065

Macintyre, H. L., Heaviside, C., Taylor, J., Picetti, R., Symonds, P., Cai, X.-M., \& Vardoulakis, S. (2018). Assessing urban population vulnerability and environmental risks across an urban area during heatwaves - Implications for health protection. Science of the Total Environment, 610-611, 678-690. https://doi.org/10.1016/j.scitotenv.2017.08.062

Marando, F., Salvatori, E., Sebastiani, A., Fusaro, L., \& Manes, F. (2019). Regulating Ecosystem Services and Green Infrastructure: assessment of Urban Heat Island effect mitigation in the municipality of Rome, Italy. Ecological Modelling, 392, 92-102. https://doi.org/10.1016/J.ECOLMODEL.2018.11.011

Martilli, A., Clappier, A., \& Rotach, M. W. (2002). An urban surface exchange parameterisation for mesoscale models. Boundary-Layer Meteorology, 104(2), 261-304. Retrieved from http://www.scopus.com/inward/record.url?eid=2-s2.00036681625\&partnerID=40\&md5=43c37de719b884fdca95e02b9e8d3ef2

Méndez-Lázaro, P., Muller-Karger, F. E., Otis, D., McCarthy, M. J., \& Rodríguez, E. (2018). A heat vulnerability index to improve urban public health management in San Juan, Puerto Rico. International Journal of Biometeorology, 62(5), 709-722. https://doi.org/10.1007/s00484-017-1319-z

Milojevic, A., Armstrong, B. G., Gasparrini, A., Bohnenstengel, S. I., Barratt, B., \& Wilkinson, P. (2016). Methods to Estimate Acclimatization to Urban Heat Island Effects on Heat- and Cold-Related Mortality. Environmental Health Perspectives, 124(7). https://doi.org/10.1289/ehp.1510109

Mitchell, B., \& Chakraborty, J. (2015). Landscapes of thermal inequity: disproportionate exposure to urban heat in the three largest US cities. Environmental Research Letters, 10(11), 115005. https://doi.org/10.1088/1748-9326/10/11/115005

Mitchell, D., Heaviside, C., Vardoulakis, S., Huntingford, C., Masato, G., P Guillod, B., ... Allen, M. (2016). Attributing human mortality during extreme heat waves to anthropogenic climate change. Environmental Research Letters, 11(7), 074006. https://doi.org/10.1088/1748-9326/11/7/074006

Morini, E., Touchaei, A. G., Rossi, F., Cotana, F., \& Akbari, H. (2018). Evaluation of albedo 
enhancement to mitigate impacts of urban heat island in Rome (Italy) using WRF meteorological model. Urban Climate, 24, 551-566.

https://doi.org/10.1016/J.UCLIM.2017.08.001

Oke, T. R. (1973). City size and the urban heat island. Atmospheric Environment, 7(8), 769779. https://doi.org/http://dx.doi.org/10.1016/0004-6981(73)90140-6

Oke, T. R. (1982). The energetic basis of the urban heat island. Quarterly Journal of the Royal Meteorological Society, 108(455), 1-24. https://doi.org/10.1002/qj.49710845502

Oke, T. R. (1987). Boundary Layer Climates. 2nd Edition, Methuen Co., London, New York.

Pasetto, M., Pasquini, E., Giacomello, G., \& Baliello, A. (2019). Innovative pavement surfaces as urban heat islands mitigation strategy: chromatic, thermal and mechanical characterisation of clear/coloured mixtures. Road Materials and Pavement Design, 20(sup1), S533-S555. https://doi.org/10.1080/14680629.2019.1593230

Patz, J. A., Campbell-Lendrum, D., Holloway, T., \& Foley, J. A. (2005). Impact of regional climate change on human health. Nature, 438(7066), 310-317. Retrieved from http://www.scopus.com/inward/record.url?eid=2-s2.0-27844536963\&partnerID=40

Peterson, T. C. (2003). Assessment of Urban Versus Rural In Situ Surface Temperatures in the Contiguous United States: No Difference Found. Journal of Climate, 16(18), 29412959. https://doi.org/10.1175/1520-0442(2003)016<2941:AOUVRI >2.0.CO;2

Phelan, P. E., Kaloush, K., Miner, M., Golden, J., Phelan, B., Silva III, H., \& Taylor, R. A. (2015). Urban Heat Island: Mechanisms, Implications, and Possible Remedies. Annual Review of Environment and Resources. Annual Reviews Inc. https://doi.org/10.1146/annurev-environ-102014-021155

Pisello, A. L. (2017). State of the art on the development of cool coatings for buildings and cities. Solar Energy, 144, 660-680. https://doi.org/10.1016/J.SOLENER.2017.01.068

Price, A., Jones, E. C., \& Jefferson, F. (2015). Vertical Greenery Systems as a Strategy in Urban Heat Island Mitigation. Water, Air, and Soil Pollution, 226(8). https://doi.org/10.1007/s11270-015-2464-910.1289/ehp.1408254; Fontana, L., Atella, V., Kammen, D.M., Energy efficiency as a unifying principle for human, environmental, and global health (2013) F1000Research, 2, p. 101; Hardy, J., (2003) Climate Change: Causes, Effects, and Solutions, , John Wiley \& Sons England; (2009) Environmental Protection Agency, , Heat Island Effect Glossary; Hunt, K.S., Passive air exchanges between building and urban canyon via openings in a single facade (2008) International Journal

Public Health England. (2015). Heatwave plan for England.

Pyrgou, A., \& Santamouris, M. (2018). Increasing Probability of Heat-Related Mortality in a Mediterranean City Due to Urban Warming. International Journal of Environmental Research and Public Health, 15(8). https://doi.org/10.3390/ijerph15081571

Robine, J.-M., Cheung, S. L. K., Le Roy, S., Van Oyen, H., Griffiths, C., Michel, J.-P., \& Herrmann, F. R. (2008). Death toll exceeded 70,000 in Europe during the summer of 2003. Comptes Rendus Biologies, 331(2), 171-178. Retrieved from http://www.sciencedirect.com/science/article/pii/S1631069107003770

Salamanca, F., Martilli, A., Tewari, M., Chen, F., Salamanca, F., Martilli, A., ... Chen, F. (2011). A Study of the Urban Boundary Layer Using Different Urban Parameterizations and High-Resolution Urban Canopy Parameters with WRF. Journal of Applied Meteorology and Climatology, 50(5), 1107-1128.

https://doi.org/10.1175/2010JAMC2538.1

Salata, F., Golasi, I., Petitti, D., de Lieto Vollaro, E., Coppi, M., \& de Lieto Vollaro, A. (2017). Relating microclimate, human thermal comfort and health during heat waves: An analysis of heat island mitigation strategies through a case study in an urban outdoor environment. Sustainable Cities and Society, 30, 79-96. 
https://doi.org/10.1016/J.SCS.2017.01.006

Salmond, J. A., Tadaki, M., Vardoulakis, S., Arbuthnott, K., Coutts, A., Demuzere, M., ...

Wheeler, B. W. (2016). Health and climate related ecosystem services provided by street trees in the urban environment. Environmental Health: A Global Access Science Source, 15. https://doi.org/10.1186/s12940-016-0103-6

Sanchez-Guevara, C., Núñez Peiró, M., Taylor, J., Mavrogianni, A., \& Neila González, J. (2019). Assessing population vulnerability towards summer energy poverty: Case studies of Madrid and London. Energy and Buildings, 190, 132-143. https://doi.org/10.1016/J.ENBUILD.2019.02.024

Scott, A. A., Waugh, D. W., \& Zaitchik, B. F. (2018). Reduced Urban Heat Island intensity under warmer conditions. Environmental Research Letters, 13(6), 064003. https://doi.org/10.1088/1748-9326/aabd6c

Sharma, A., Woodruff, S., Budhathoki, M., Hamlet, A. F., Chen, F., \& Fernando, H. J. S. (2018). Role of green roofs in reducing heat stress in vulnerable urban communities - a multidisciplinary approach. Environmental Research Letters, 13(9), 094011. https://doi.org/10.1088/1748-9326/aad93c

Sherman, P., \& Archibald, A. (2019). The Urban Heat Island (UHI) is a major source of uncertainty in projections of population-weighted surface temperature under climate change. https://doi.org/10.31223/OSF.IO/GPCYW

Silva, H. R., Phelan, P. E., \& Golden, J. S. (2010). Modeling effects of urban heat island mitigation strategies on heat-related morbidity: A case study for Phoenix, Arizona, USA. International Journal of Biometeorology, 54(1), 13-22. https://doi.org/10.1007/s00484-009-0247-y

Steeneveld, G. J., Koopmans, S., Heusinkveld, B. G., \& Theeuwes, N. E. (2014). Refreshing the role of open water surfaces on mitigating the maximum urban heat island effect. Landscape and Urban Planning, 121, 92-96. https://doi.org/10.1016/J.LANDURBPLAN.2013.09.001

Stewart, I. D. (2011). A systematic review and scientific critique of methodology in modern urban heat island literature. International Journal of Climatology, 31(2), 200-217. https://doi.org/10.1002/joc.2141

Stewart, I. D., \& Oke, T. R. (2012). Local climate zones for urban temperature studies. Bulletin of the American Meteorological Society, 93(12), 1879-1900. https://doi.org/10.1175/BAMS-D-11-00019.1

Stone Jr, B., Vargo, J., Liu, P., Habeeb, D., DeLucia, A., Trail, M., ... LoSchiavo, A. (2014). Avoided heat-related mortality through climate adaptation strategies in three US cities. PLoS ONE, 9(6), e100852. https://doi.org/10.1371/journal.pone.010085210.1029/2012JD018091; Lynn, B., Rosenzweig, C., Goldberg, R., Rind, D., Hogrefe, C., Testing GISS-MM5 physics configurations for use in regional impacts studies (2010) Climatic Change, 99, pp. 567587; Spronken-Smith, R.A., Oke, T.R., The thermal regime of urban parks in two cities with different summer climates (1998) International Journal of Remote Sensing, 19 (11), pp. 2085-2104; Hart, M., Sailor, D., Quantifying the influence of land-use and surface characteristi

Sun, C.-Y., Kato, S., Gou, Z., Sun, C.-Y., Kato, S., \& Gou, Z. (2019). Application of LowCost Sensors for Urban Heat Island Assessment: A Case Study in Taiwan. Sustainability, 11(10), 2759. https://doi.org/10.3390/su11102759

Susca, T. (2012). Multiscale Approach to Life Cycle Assessment: Evaluation of the Effect of an Increase in New York City's Rooftop Albedo on Human Health Susca, LCA: Rooftop Albedo and Human Health. Journal of Industrial Ecology, 16(6), 951-962. https://doi.org/10.1111/j.1530-9290.2012.00560.x 10.1029/2009GL042194; Owens, 
J.W., Life-cycle assessment: Constraints on moving from inventory to impact assessment (1997) Journal of Industrial Ecology, 1 (1), pp. 37-49; Patz, J.A., McGeehin, M.A., Bernard, S.M., Ebi, K.L., Epstein, P.R., Grambseh, A., Gubler, D.J., Trtanjl, J., The potential health impacts of climate variability and change for the United States: Executive summary of the report of the health sector of the U.S. national assessment (2000) Environ

Taha, H., Levinson, R., Mohegh, A., Gilbert, H., Ban-Weiss, G., Chen, S., ... Chen, S. (2018). Air-Temperature Response to Neighborhood-Scale Variations in Albedo and Canopy Cover in the Real World: Fine-Resolution Meteorological Modeling and Mobile Temperature Observations in the Los Angeles Climate Archipelago. Climate, 6(2), 53. https://doi.org/10.3390/cli6020053

Taylor, J., Symonds, P., Wilkinson, P., Heaviside, C., Macintyre, H., Davies, M., ... Hutchinson, E. (2018). Estimating the influence of housing energy efficiency and overheating adaptations on heat-related mortality in the West Midlands, UK. Atmosphere, 9(5). https://doi.org/10.3390/atmos9050190

Taylor, J., Wilkinson, P., Davies, M., Armstrong, B., Chalabi, Z., Mavrogianni, A., ... Bohnenstengel, S. I. (2015). Mapping the effects of urban heat island, housing, and age on excess heat-related mortality in London. Urban Climate, 14, 517-528. https://doi.org/10.1016/j.uclim.2015.08.001

Teotónio, I., Silva, C. M., \& Cruz, C. O. (2018). Eco-solutions for urban environments regeneration: The economic value of green roofs. Journal of Cleaner Production, 199, 121-135. https://doi.org/10.1016/J.JCLEPRO.2018.07.084

Theeuwes, N. E., Steeneveld, G.-J., Ronda, R. J., \& Holtslag, A. A. M. (2017). A diagnostic equation for the daily maximum urban heat island effect for cities in northwestern Europe. International Journal of Climatology, 37(1), 443-454. https://doi.org/10.1002/joc.4717

Tollefson, J. (2011). Different method, same result: global warming is real. Nature. https://doi.org/10.1038/news.2011.607

Tomlinson, C. J., Chapman, L., Thornes, J. E., \& Baker, C. J. (2011). Including the urban heat island in spatial heat health risk assessment strategies: A case study for Birmingham, UK. International Journal of Health Geographics, 10. Retrieved from http://www.scopus.com/inward/record.url?eid=2-s2.079958812539\&partnerID=40\&md5=64dc6e83ef9d82d9bd17bb0f1e4ded40

United Nations. (2014). United Nations. Department of Economic and Social Affairs, Population Division, World Urbanization Prospects: The 2014 Revision. Published by the United Nations, ISBN 978-92-1-15157-6, Copyright (C) United Nations, 2014.

Vardoulakis, S., Dear, K., \& Wilkinson, P. (2016). Challenges and Opportunities for Urban Environmental Health and Sustainability: The HEALTHY-POLIS initiative.

Environmental Health: A Global Access Science Source, 15. https://doi.org/10.1186/s12940-016-0096-1

Vargo, J., Stone, B., Habeeb, D., Liu, P., \& Russell, A. (2016). The social and spatial distribution of temperature-related health impacts from urban heat island reduction policies. Environmental Science \& Policy, 66, 366-374. https://doi.org/10.1016/j.envsci.2016.08.012

Voelkel, J., Hellman, D., Sakuma, R., \& Shandas, V. (2018). Assessing Vulnerability to Urban Heat: A Study of Disproportionate Heat Exposure and Access to Refuge by Socio-Demographic Status in Portland, Oregon. International Journal of Environmental Research and Public Health, 15(4). https://doi.org/10.3390/ijerph15040640

Wang, J., Kuffer, M., Sliuzas, R., \& Kohli, D. (2019). The exposure of slums to high temperature: Morphology-based local scale thermal patterns. Science of The Total 
Environment, 650, 1805-1817. https://doi.org/10.1016/J.SCITOTENV.2018.09.324

Wheeler, B. W., Lovell, R., Higgins, S. L., White, M. P., Alcock, I., Osborne, N. J., ...

Depledge, M. H. (2015). Beyond greenspace : an ecological study of population general health and indicators of natural environment type and quality. International Journal of Health Geographics, 1-17. https://doi.org/10.1186/s12942-015-0009-5

Wolf, T., \& McGregor, G. (2013). The development of a heat wave vulnerability index for London, United Kingdom. Weather and Climate Extremes, 1, 59-68. https://doi.org/10.1016/j.wace.2013.07.004

Woods, M., Crabbe, H., Close, R., Studden, M., Milojevic, A., Leonardi, G., ... Chalabi, Z. (2016). Decision support for risk prioritisation of environmental health hazards in a UK city. Environmental Health, 15(1). https://doi.org/10.1186/s12940-016-0099-y

Zhang, W., Zheng, C., \& Chen, F. (2019). Mapping heat-related health risks of elderly citizens in mountainous area: A case study of Chongqing, China. Science of The Total Environment, 663, 852-866. https://doi.org/10.1016/J.SCITOTENV.2019.01.240

Zhang, Y., Murray, A. T., \& Turner, B. L. (2017). Optimizing green space locations to reduce daytime and nighttime urban heat island effects in Phoenix, Arizona. Landscape and Urban Planning, 165, 162-171. https://doi.org/10.1016/J.LANDURBPLAN.2017.04.009

Zinzi, M., \& Agnoli, S. (2012). Cool and green roofs. An energy and comfort comparison between passive cooling and mitigation urban heat island techniques for residential buildings in the Mediterranean region. Energy and Buildings, 55, 66-76. https://doi.org/10.1016/j.enbuild.2011.09.024 